\title{
Neuroglia - development and role in physiological and pathophysiological processes
}

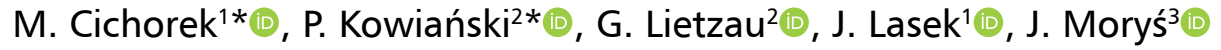 \\ ${ }^{1}$ Department of Anatomy and Physiology, Pomeranian University of Stupsk, Poland \\ 2Department of Anatomy and Neurobiology, Faculty of Medicine, Medical University of Gdansk, Poland \\ ${ }^{3}$ Department of Normal Anatomy, Pomeranian Medical University, Szczecin, Poland
}

[Received: 27 September 2021; Accepted: 29 September 2021; Early publication date: 21 October 2021]

The dynamic development of studies on neuroglia in recent years indicates its previously underestimated role in maintaining proper brain function, both in physiological and pathological conditions. The use of modern research methods such as single-cell techniques as well as in vivo and in vitro models enriched the state of our knowledge. The most important issues regarding the maturation and development of neuroglia include cooperation between glial cell groups and with neurons in neurogenesis, neuroregeneration, (re)myelination and how the early developmental roles of glia contribute to nervous system dysfunction in neurodevelopmental and neurodegenerative disorders.

There is still growing evidence emphasizing the importance of astroglia in maintaining the brain physiological homeostasis, regulation of immune response, cerebral blood flow, and involvement in the reactive neurogliosis, precisely adapted to the nature of pathological stimulus and the depth of tissue damage. The important issues related to the function of oligodendrocytes include explanation of the mechanisms of interaction between the glial cells and myelinated axons, important not only in myelination, but also in development of cognitive processes and memory. Further studies are required for understanding the mechanisms of demyelination occurring in several central nervous system (CNS) diseases. An interesting area of research is related with explanation of the NG2 glia function, characterised by significant proliferative potential and ability to differentiate in both in physiological conditions and in pathology, as well as the presence of synaptic neural-glial connections, which are especially numerous during development. The increasing knowledge of microglia comprises the presence of specialised subsets of microglia, their role the myelination process and neurovascular unit functioning. We are only beginning to understand how microglia enter the brain and develop distinct functional states during ontogeny.

This review summarises the current state of knowledge on the development and role in the CNS of different, heterogeneous cell populations defined by a common term neuroglia. (Folia Morphol 2021; 80, 4: 766-775)

Key words: astrocytes, microglia, NG2 cells, neurovascular unit, oligodendrocytes

Address for correspondence: Dr. M. Cichorek, Medical University of Gdansk, Faculty of Medicine, Department of Embryology, ul. Dębinki 1, 80-211 Gdańsk, Poland, tel: +48 58349 1496, e-mail: miroslawa.cichorek@gumed.edu.pl; Prof. P. Kowiański, Medical University of Gdansk, Faculty of Medicine, Department of Anatomy and Neurobiology, ul. Dębinki 1, 80-211 Gdańsk, Poland, tel: +48 58349 1819, e-mail: przemyslaw.kowianski@gumed.edu.pl *These authors contributed equally to this work.

This article is available in open access under Creative Common Attribution-Non-Commercial-No Derivatives 4.0 International (CC BY-NC-ND 4.0) license, allowing to download articles and share them with others as long as they credit the authors and the publisher, but without permission to change them in any way or use them commercially. 


\section{INTRODUCTION}

The increasing evidence suggests previously overlooked, important role of neuroglia in the brain physiological and pathological processes [92, 94]. This justifies the need to abandon the "neurocentric" perspective in understanding the nervous tissue functioning. In physiological conditions, the neuroglia participates in developmental processes including neuro-, glio- and synaptogenesis, in control of metabolic processes, immune response and myelination of nerve fibres [14]. It is also involved in the brain functional integration, through the modulation of neuroplasticity and shaping cognitive and memory processes. Other important issues comprise gliotransmission and regulation of the cerebral blood flow. Following, a synthetic summary of the most important information regarding neuroglial development, morphology and function is presented. The neurglial cells consist of three main types, astrocytes, oligodendrocytes and microglia.

\section{GLIAL CELLS ORIGIN}

Based on the developmental origin, two groups of central nervous system (CNS) glial cells can be distinguished: macroglia and microglia. Macroglia (i.e. astrocytes, oligodendrocytes), like neurons, originate from the epithelium of the neural tube (neuroectoderm). Microglia, in contrast, derive from mesoderm of the yolk sac wall $[52,60]$.

\section{Macroglia}

During the fourth week, embryonic disc follows morphological changes, as the result of ongoing differentiation of the germ layer cells. At that time, the neurulation takes place and, in a result, the neural tube (primordium for CNS) forms on the basis of neuroectodermal cells. After closing the anterior and posterior neuropores, the neural tube cells proliferate and follow differentiation into neurons and macroglial cells. The neural tube wall is formed by a pseudostratified epithelium with high rate of proliferation from the inner cavity side (future ventricles and central canal). Cytodifferentiation of the neural tube wall cells leads to an emergence of neurons and macroglia. Early glial cells called radial glial cells (glial progenitor cells) build pathways for neurons migration and are precursors for astrocytes and oligodendrocytes $[19,52,77]$. It is also a time of neuronal functional differentiation into motoneurons and interneurons, and glia provide metabolic and structural support to these neurons $[19,77]$. Neuronal number during embryogenesis is modulated by a programmed cell death that is crucial for proper CNS development. Neuronal death is a result of a balance between the prosurvival and death-inducing factors, and glial cells are active players in this process [52]. Since other types of glia, such as astrocytes and oligodendrocytes, are generated during late embryogenesis after neuroblasts have produced most neurons, microglia constitute the main population of glial cells during early embryogenesis [52].

\section{Microglia}

Early entry and the brain colonization enables microglia to perform critical roles in regulating important events of early brain development, e.g. neurons' survival, phagocytosis of dying neurons, synaptogenesis, angiogenesis, axons development [78]. Microglia originate from the embryonic erythromyeloid progenitors of the yolk sac, and not from the haematopoietic stem cells [54]. These cells of the macrophage nature arise early in embryogenesis (during the fourth week) and invade the developing neural tube, where they differentiate as the result of factors action provided by their neural niche [64]. Yolk sac is the embryonic membrane where the vasculogenesis process takes place. As the result of this process first embryonic vessels and blood cells are being formed $[19,77]$. Thus, from fourth to eighth week yolk sac is the place of the embryonic haematopoiesis. Primitive macrophages reach the blood vessels and also the neural tube [8, 84]. Microglia constitute the first and main population of glial cells during early embryogenesis, thus, their differentiation is strongly linked to the neural tissue maturation. Once invading the forming central nervous system, in this early embryogenesis, the microglial cells expand via proliferation without input of foetal monocytes or bone marrow-derived progenitors during later developmental stages $[54,95]$. Thus, microglia self-renew via proliferation and are not replaced by bone marrow-derived cells in the healthy brain. Only in the case of injury, inflammation, disease or blood brain barrier break down, these cells are supported by infiltrating bone-marrow-derived monocytes [54, 95]. Therefore, microglia show a high ability to proliferation during prenatal and postnatal stages to expand and distribute in the developing CNS, but in adult stage there is a decline in proliferation $[62,86]$.

In addition to microglia located inside the nervous tissue (parenchyma), there are CNS-associated mac- 
rophages located in meninges, perivascular area, and choroid plexus that also originate from the yolk sac progenitors [32]. Yolk-sac primary macrophages are heterogeneous even before brain colonisation. However, role of these other macrophages remains largely unknown [89]. Only choroid plexus macrophages are replaced over time by the circulating monocytes [32].

\section{GLIAL CELLS CHARACTERISTIC}

\section{Astrocytes}

Apart from the star-shaped cellular body, reflected in the name of this class of neuroglia, characteristic features of the astrocytes include presence of the intermediate filaments (e.g. glial fibrillary acidic protein and vimentin) building their cytoskeleton, perivascular projections and gap junctions, and presence of glutamate and GABA transporters [46-48]. Among their characteristic features are also specific properties of energy metabolism and lack of electrical excitability $[43,49]$. Apart from the protoplasmic and fibrous astrocytes, there are several other types distinguished, defined by different structure and immunocytochemical characteristics [63]. The differences in the morphology and biochemical features reflect considerable variability in astrocytic function, which is still only partially disclosed.

In physiological conditions, astrocytes have several functions mainly related with maintaining the physiological homeostasis $[44,79,80]$. Among them, the most important are: regulation of metabolic processes in the brain tissue (e.g. regulation of glucose metabolism, ion concentration, water content, and $\mathrm{pH})$, structural support (creating functional barriers, territorial domains and syncytial structures), brain development (proliferation, gliogenesis, neuroplasticity), intercellular communication (gliotransmission, regulation of synaptic transmission and plasticity), neuroprotection and brain defence (regulation of cerebral blood flow, protection against glutamatergic excitotoxicity, and inflammatory response).

One of the most important features of astrocytes, which determines their function in pathological conditions, is greater than in the case of other neuroglial subpopulations resistance to decrease in oxygen and glucose concentrations [98]. This enables preserving anaerobic glycolysis and ATP production in the area of brain damage and, consequently, supporting the neuronal metabolic functions [59]. Due to the abovementioned features, astrocytes are involved in processes initiated in the brain tissue by pathological stimuli and defined as the reactive neurogliosis [80]. This neuroglial response comprises the morphological changes, changes in gene expression, activation of signalling pathways, activation of the inflammatory reactions, and interactions among the various neuroglial populations initiated by the damaging factor $[2,26,80]$. However, on the contrary to the previously accepted views, it is not regarded as a stereotypical reaction independent of the nature of the pathological stimulus $[2,13,79]$. The astrocytic response is multipotent and context-dependent, optimally adapted to the type of injury, its intensity and the time passed since its initiation $[2,55,79]$. The processes involved in the reactive neurogliosis are both of destructive and protective character $[45,55]$. Each of them reaches its maximal intensity at the specific time-point determining the further fate of the damaged tissue, as well as potential therapeutic measures. The destructive effects of astrogliosis include an exacerbation of the inflammatory response resulting from pro-inflammatory cytokine production, release of reactive oxygen species and excitotoxic glutamate, and impairment of the blood-brain barrier (BBB) function $[79,81]$. The protective effects include an excitotoxic glutamate uptake, protection against the oxidative stress by free radical scavenging, the BBB repair and reduction of the vasogenic oedema, and neurotrophin release [25, $27,79]$. Another characteristic feature of the reactive neurogliosis is presence of phenotypical characteristics not observed in the resting conditions and an expression of several antigens typical for the earlier stages of the cellular lineage development [10-12]. All these processes enable restoration of the functions impaired by the pathological stimuli and demarcation of the destructive effects of damage, meanwhile protecting the intact brain tissue areas. The fact that astrocytes communicate with neurons and the vascular system after injury makes them potentially useful in future regenerative therapeutic strategies.

\section{Oligodendrocytes}

The morphological classification of oligodendrocytes is based on a diversity of their body shapes, number of processes, and size of myelinated axons $[17,66]$. According to these criteria, four morphological types of oligodendrocytes are distinguished. Additionally, the non-myelinating oligodendrocytes, such as perineuronal satellite oligodendrocytes and, according to some researchers, NG2 glial cells can be identified $[16,67]$. The most important function 
of oligodendrocytes is production of myelin sheath. The number of the neuronal extensions myelinated by a single oligodendrocyte unit may reach up to 30 axons [70]. However, this number shows great variability. The close relationship between the oligodendrocyte and the myelinated fragments of the axons enables an interaction that occurs through the ligand- and voltage-gaited ion channels and receptors, which is important for communication between oligodendrocytes and neurons [15, 18, 72]. This direct structural relationship affects, on the one hand, the course of the myelination process and, on the other hand, the conduction of the action potential along the axon. The mutual contact between the oligodendrocyte and neuronal axon determines the maintenance of the physiological efficiency of oligodendrocytes, protecting them against damage resulting from the excessive concentration of neurotransmitters or the excessive activity of ion channels $[15,18]$. It has been reported that effectiveness of this communication is the highest in the oligodendrocyte progenitor cells $(\mathrm{OPC})$ and gradually decreases during the ontogenic development [29].

In pathological conditions, oligodendrocyte functional impairment is manifested by a demyelination. It might be a result of improper immunological response induced by external and internal stimuli occurring in the course of demyelinating diseases (e.g. multiple sclerosis) [76]. The myelin damage has also been demonstrated during aging and in some neuropsychological illnesses, such as schizophrenia or bipolar disorder, as well as in the course of Alzheimer's disease and cognitive disorders $[7,30,51]$.

\section{Microglia}

In the prenatal and early postnatal phase, microglia actively participate in brain development by stimulating neurogenesis and gliogenesis (e.g. oligodendrocytes), and the brain vasculature. Microglia regulate the neural circuit wiring, apoptosis and survival of neurons, synapse formation and functioning, and myelination $[52,78]$. Thus, microglia are considered either a causal or a contributing factor to almost all brain disorders, from neurodevelopmental disorders to neurodegeneration. In humans and mice, microglia represent around $10 \%$ of the adult CNS cells, with variable cell density across distinct CNS regions [53, 69]. We are only starting to understand how microglia enter the brain and develop distinct functional states during ontogeny.
Under homeostatic conditions microglia are longlived, self-renewing cells that constantly control the CNS environment $[54,95]$. Little is known about microglia specific role in the brain during normal growth and development. Microglia activation is a common feature in neurological disorders based on inflammation, demyelination or neuronal structure degeneration, and also in glioma development $[54,60,95]$. Microglia are the glial cells that form the first line of immune defence in the brain and spinal cord. Tissue damage induces activation of microglia cells which secrete a broad range of cytokines with either pro- or anti-inflammatory properties $[52,95]$. Activated microglia can influence other glial cells and increase the BBB permeability $[52,95]$. Thus, activated microglia enhance their phagocytic functions in order to clear the damaged tissue from remnants of myelin, cellular debris, apoptotic bodies, and pathogens $[52,78]$.

Microglia have been distinguished based on their morphology and surface molecules presence, which proves that they are a heterogeneous cell population within the CNS [35]. Additionally, one can observe a variety of biologically important functions of these cells, supported by the presence of specialised subsets of microglia. It has been postulated that there are three microglial developmental stages: early microglia (high rate of proliferation and differentiation), pre-microglia linked to neuronal development, and adult microglia [4]. Animal studies using mice model of brain development have shown that early during postnatal development a $\mathrm{CD} 11 \mathrm{c}^{+}$microglia are involved in the myelination process $[82,96]$, and that this cell population is of special importance in progress of different CNS diseases and during aging [4].

There have been trials to define a precise molecular signature of microglial cells [52, 78]. Microglia have a unique gene signature determined by the microglia-specific genes, such as Tmem119, P2ry12, Sall1, and Olfml3 [5]. Microglia also express many genes shared by macrophages, including CD11b, CD45, and CX3CR1 $[4,5]$. Results of animal studies have indicated that microglia subtypes emerge in brain regions or disease development [61]. Interestingly, there has been observed a regional heterogeneity of microglia in the human brain [9]. Each brain region represents a distinct niche (i.e. has its own neuronal populations, glial cells content, extracellular matrix components). During brain angiogenesis, microglia secret factors that influence vascular growth [57]. 
Two signalling pathways are crucial for microglial development: one involves colony stimulating factor 1 receptor (CSF1R) and the second one - transforming growth factor beta (TGF-beta). Studies have shown that deletion or inhibition of the CSF1R during mice development results in loss of microglia [36, 86]. CSF1R has two ligands, interleukin 34 (IL-34) and CSF1. Both are expressed in the CNS, but each of them has a different source established postnatally, e.g. grey matter microglia depend on neuronal IL-34 production, while white matter microglia depend on CSF1 secreted by astrocytes after birth $[36,86]$. Loss of TGF-beta signalling in adult microglia results in their hyperactivation after birth and impairment of microglial expansion throughout the developing CNS $[36,86]$. Thus, microglial cells need neurons to survive and differentiate. Neurons secret the cytokines IL-34 and CSF1 that influence the CSF1R pathway, as well as ligands for TGF-beta signalling [42].

Another major factor influencing microglial biology is the gut microbiome. Results of studies in the germ-free mice have shown maturation disturbances of adult microglia [86]. Signals from the microbiome affect microglia mainly during postnatal development, whereas embryonic microglia are less sensitive to the microbiota $[36,86]$.

Like other tissue-resident macrophages, microglia phagocytize cell debris, respond to inflammatory factors, and patrol the local microenvironment. Microglia influence the nervous tissue through a different cellular functions controlled by intrinsic and extrinsic factors. During development, microglia participate in synaptogenesis, modulate axonal growth, secrete factors that support the postnatal survival of the cortical neurons, e.g. insulin-like growth factor 1 (IGF-1). Microglia also are involved in the physiological functions in the adult CNS, as they constantly control their environment.

Animal studies have shown that amoeboid microglia in white matter are essential for proper oligodendrocyte homeostasis and myelinogenesis $[82,96]$. Wlodarczyk et al. [96] discovered a new role for of $\mathrm{CD} 11 \mathrm{c}^{+}$microglia in promoting the CNS myelination. The molecule CD11c is a classic dendritic cell surface marker and only very few microglial cells in the normal adult brain express a detectable level of this protein. This subset of microglia also express sevenfold more mRNA for IGF-1 than their CD11c counterparts, and it has significantly higher levels compared with neurons, astrocytes, and oligodendrocyte precursor cells [96].
This population of microglia predominates in the primary areas of the brain myelination and its selective depletion provides to myelin formation disturbances [96]. It has also been suggested that early after birth the white matter microglial cells differ from the grey matter microglial cells [82].

\section{NG2 cells}

NG2 glial cells are classified as a distinct fourth population of neuroglia, accounting for approximately $5 \%$ of neuroglial population and identified by the co-expression of chondroitin sulphate proteoglycan NG2 and platelet-derived growth factor receptor alfa $[67,71]$. Most of them are thought to represent oligodendrocyte lineage [73, 99]. Some authors consider them to be the OPC, sometimes even using the terms OPC and NG2 glia interchangeably. In the adult brain they remain as the NG2 glial cells or differentiate into oligodendrocytes, although this feature varies among the brain areas $[67,71]$.

The most important features of NG2 glia are the significant proliferative capacity and differentiation potential still present in the adult brain $[23,24,91]$. In physiological conditions, they allow to maintain a stable number of NG2 cells and oligodendrocytes $[67,71]$. Other functions of NG2 cells in physiological conditions include: regulation of the cell migration, re-myelination and efficiency of synaptic conduction, and keeping the energetic metabolism at the adequate level [28, 40, 74]. The NG2 glia form synapses receiving the GABA-ergic and glutamatergic neuronal inputs [22]. The role of the neuro-glial synapses is most probably related to increase of proliferation and oligodendrocyte differentiation [22]. Another characteristic feature of the NG2 neuroglia is an occurrence of spontaneous and evoked synaptic currents, although their function is unknown [6].

The most important features of NG2 glia in pathological conditions are: the significant proliferative potential and differentiation ability preserved in adulthood, which enable their contribution to the re-population of different neuroglial classes reduced due to destructive processes in the CNS $[38,90]$. This role has been demonstrated in many experimental models of brain lesion, both in vitro and in vivo [24, $33,65,90,97]$. The ability of NG2 cells to differentiate into astrocytes and oligodendrocytes [37, 91], as well as their contribution to increasing NG2 glia population have been proved by several authors [67, 71]. However, the NG2 cells ability to differentiate 
into neurons, suggested by some authors, has not been commonly accepted $[87,88]$. Reassuming, the morphological features of the NG2 glia response and its proliferation potential depend on the type of pathological stimulus and degree of tissue damage [90]. The function of NG2 glia in pathological conditions is only partially understood and requires further intensive research. The proliferative and differentiative potential of NG2 glia could be attractive for development of regenerative medicine therapeutic strategies.

\section{NEUROVASCULAR UNIT}

Regulation of physiological processes in the CNS requires involvement of all structural components of the nervous tissue. This is particularly evident in the case of the regulation of cerebral blood flow, characterised by enormous dynamics and requiring adaptation of changes to the current biochemical conditions in the brain, as well as to the physiological parameters, determining the state of the circulatory system [100].

The concept of the neurovascular unit (NVU) has proven useful in studies on the structure and function of the brain tissue in physiological and pathological conditions [31, 41, 75]. This theoretical model comprehensively describes morphological and functional relationships occurring among three main components of brain tissue: neurons, neuroglia and cerebral vessels. Apart from neurons, the NVU consists of the vascular endothelial cells, smooth muscle cells of the vascular wall, pericytes, astrocytes and perivascular macrophages [1, 20, 57]. The unquestionable value of the NVU model in explaining the essence of many physiological and pathological processes, as well as its usefulness in elucidating the complex regulatory mechanisms occurring between its components, results from the interaction of several structures. Among them one could encounter: tripartite synapses (ensuring the possibility of the synaptic activity modulation by the astrocyte) [3, 34], astrocytic perivascular end-feet (enabling direct action of the astrocyte on the vascular wall) [85], and vascular tight junctions (being an essential component of the BBB) [1]. Astrocytes control the maintenance of these tight-junctions by secreting factors, e.g. sonic hedgehog protein (Shh), beta-catenin. However, the activated astrocytes can disrupt the local BBB allowing an entry of the peripheral immune cells. The efficient functioning of the NVU is also a result of action the signalling systems based on gliotransmission [93] and $\mathrm{Ca}^{2+}$ oscillations $[50,68,101]$. The NVU is characterised by involvement of its elements in numerous biochemical processes, heterogeneous resistance of its constituents to metabolic disorders occurring in the course of CNS diseases, differentiated participation in the immune response induced by pathological stimuli and, finally, by different proliferative and regenerative potential of the cellular lineages $[31,41]$. The NVU concept has proven to be very useful in research on several issues, such as regulation of the cerebral blood flow, status of the BBB, dysfunctions of the neurotransmitter systems and signalling pathways. It has also proven its value in the studies on coexistence of different pathological processes, as well as diseases at different stages in patients of various age, such as atherosclerosis, hyperlipidaemia, Alzheimer's, cardiovascular and inflammatory diseases [21, 41, 50, 75]. Steliga et al. [83] have also suggested that the NVU could be a source of biomarkers useful for cerebral stroke diagnostics.

The crosstalk between microglia and astrocytes in the BBB is crucial during inflammatory processes in the CNS. Microglia and astrocytes are activated into the pro-inflammatory phenotype and the anti-inflammatory phenotype $[56,58]$. Activated into the M1 phenotype microglia produce pro-inflammatory factors, such as IL-1 and TNF-alfa that activate astrocytes. Subsequently, microglia change morphology, i.e. take an amoeboid shape and increase ability to phagocytosis [58]. As a macrophages, microglial cells function also in $\mathrm{M} 2$ phenotype secreting anti-inflammatory factors, such as IL-10, TGF-beta. In general, the $\mathrm{M} 1$-like phenotype is considered to be associated with tissue destruction (including NVU), while the M2-like phenotype is involved in repair and regeneration $[57,58]$. Experimental trials have been taken to inhibit the activity of the proinflammatory phenotype of microglia and augment the activity of the anti-inflammatory phenotype of microglia, e.g. in stroke [39].

\section{CONCLUSIONS}

The last decade of research has shed a new light on glial identity and activities. It is now a well-established fact that glial cells are a very heterogeneous group of the CNS cells interacting with each other and having multiple interactions with other CNS elements to control their development and functioning. Glial cells isolated from different brain regions show age- 
and region-dependent differences in transcriptomic profiles. It has been suggested the appearance of homeostatic and reactive glial subtypes could be of great importance for understanding many CNS pathologies. Thus, the molecular characteristic of a particular glial subtype in its anatomical environment is a key to understand glial cells role in both homeostatic and pathological conditions.

\section{Funding}

This research was supported by funds provided by the Polish Ministry of Education and Science (ST-11).

Conflict of interest: None declared

\section{REFERENCES}

1. Abbott NJ, Patabendige AAK, Dolman DEM, et al. Structure and function of the blood-brain barrier. Neurobiol Dis. 2010; 37(1): 13-25, doi: 10.1016/j.nbd.2009.07.030, indexed in Pubmed: 19664713.

2. Anderson MA, Ao Y, Sofroniew MV. Heterogeneity of reactive astrocytes. Neurosci Lett. 2014; 565: 23-29, doi: 10.1016/j.neulet.2013.12.030, indexed in Pubmed: 24361547.

3. Araque A, Parpura V, Sanzgiri RP, et al. Tripartite synapses: glia, the unacknowledged partner. Trends Neurosci. 1999; 22(5): 208-215, doi: 10.1016/s0166-2236(98)01349-6, indexed in Pubmed: 10322493.

4. Benmamar-Badel A, Owens T, Wlodarczyk A. Protective microglial subset in development, aging, and disease: lessons from transcriptomic studies. Front Immunol. 2020; 11: 430, doi: 10.3389/fimmu.2020.00430, indexed in Pubmed: 32318054.

5. Bennett ML, Bennett FC, Liddelow SA, et al. New tools for studying microglia in the mouse and human CNS. Proc Natl Acad Sci U S A. 2016; 113(12): E1738-E1746, doi: 10.1073/pnas.1525528113, indexed in Pubmed: 26884166

6. Bergles $D E$, Jabs R, Steinhäuser $C$. Neuron-glia synapses in the brain. Brain Res Rev. 2010; 63(1-2): 130-137, doi: 10.1016/j.brainresrev.2009.12.003, indexed in Pubmed: 20018210.

7. Bernstein HG, Keilhoff G, Dobrowolny $H$, et al. Perineuronal oligodendrocytes in health and disease: the journey so far. Rev Neurosci. 2019; 31(1): 89-99, doi: 10.1515/ revneuro-2019-0020, indexed in Pubmed: 31323013.

8. Bian Z, Gong Y, Huang T, et al. Deciphering human macrophage development at single-cell resolution. Nature. 2020; 582(7813): 571-576, doi: 10.1038/s41586-0202316-7, indexed in Pubmed: 32499656.

9. Böttcher C, Schlickeiser S, Sneeboer MAM, et al. Human microglia regional heterogeneity and phenotypes determined by multiplexed single-cell mass cytometry. Nat Neurosci. 2019; 22(1): 78-90, doi: 10.1038/s41593-0180290-2, indexed in Pubmed: 30559476.

10. Bramanti V, Tomassoni D, Avitabile M, et al. Biomarkers of glial cell proliferation and differentiation in culture.
Front Biosci (Schol Ed). 2010; 2: 558-570, doi: 10.2741/ s85, indexed in Pubmed: 20036968.

11. Buffo A, Rite I, Tripathi $P$, et al. Origin and progeny of reactive gliosis: $A$ source of multipotent cells in the injured brain. Proc Natl Acad Sci USA. 2008; 105(9): 3581-3586, doi: 10.1073/pnas.0709002105, indexed in Pubmed: 18299565.

12. Buffo A, Rolando C, Ceruti S. Astrocytes in the damaged brain: molecular and cellular insights into their reactive response and healing potential. Biochem Pharmacol. 2010; 79(2): 77-89, doi: 10.1016/j.bcp.2009.09.014, indexed in Pubmed: 19765548.

13. Burda JE, Sofroniew MV. Reactive gliosis and the multicellular response to CNS damage and disease. Neuron. 2014; 81(2): 229-248, doi: 10.1016/j.neuron.2013.12.034, indexed in Pubmed: 24462092.

14. Butt A, Verkhratsky A. Neuroglia: Realising their true potential. Brain Neurosci Adv. 2018; 2: 2398212818817495 , doi: 10.1177/2398212818817495, indexed in Pubmed: 32166166.

15. Butt AM, Fern RF, Matute C. Neurotransmitter signaling in white matter. Glia. 2014; 62(11): 1762-1779, doi: 10.1002/glia.22674, indexed in Pubmed: 24753049.

16. Butt AM, Hamilton $N$, Hubbard P, et al. Synantocytes: the fifth element. J Anat. 2005; 207(6): 695-706, doi: 10.1111/j.14697580.2005.00458.x, indexed in Pubmed: 16367797.

17. Butt AM, Ibrahim M, Berry M. Axon-myelin sheath relations of oligodendrocyte unit phenotypes in the adult rat anterior medullary velum. J Neurocytol. 1998; 27(4): 259-269, indexed in Pubmed: 10640184.

18. Butt AM, Kalsi A. Inwardly rectifying potassium channels (Kir) in central nervous system glia: a special role for Kir4.1 in glial functions. J Cell Mol Med. 2006; 10(1): 33-44, doi: 10.1111/j.1582-4934.2006.tb00289.x, indexed in Pubmed: 16563220.

19. Carlson BM. Nervous system. In human embriology and develomental biology. 6th ed. Elsevier, Philadelphia 2019: 216-235.

20. Carmignoto G, Gómez-Gonzalo M. The contribution of astrocyte signalling to neurovascular coupling. Brain Res Rev. 2010; 63(1-2): 138-148, doi: 10.1016/j.brainresrev.2009.11.007, indexed in Pubmed: 19948187.

21. Czuba E, Steliga A, Lietzau G, et al. Cholesterol as a modifying agent of the neurovascular unit structure and function under physiological and pathological conditions. Metab Brain Dis. 2017; 32(4): 935-948, doi: 10.1007/ s11011-017-0015-3, indexed in Pubmed: 28432486.

22. De Biase LM, Nishiyama A, Bergles DE. Excitability and synaptic communication within the oligodendrocyte lineage. J Neurosci. 2010; 30(10): 3600-3611, doi: 10.1523/JNEUROSCI.6000-09.2010, indexed in Pubmed: 20219994.

23. Dimou L, Gallo V. NG2-glia and their functions in the central nervous system. Glia. 2015; 63(8): 1429-1451, doi: 10.1002/glia.22859, indexed in Pubmed: 26010717.

24. Dimou L, Simon C, Kirchhoff F, et al. Progeny of Olig2-expressing progenitors in the gray and white matter of the adult mouse cerebral cortex. J Neurosci. 2008; 28(41): 10434-10442, doi: 10.1523/JNEUROSCI.2831-08.2008, indexed in Pubmed: 18842903.

25. Dringen R, Brandmann M, Hohnholt MC, et al. Glutathione-dependent detoxification processes in as- 
trocytes. Neurochem Res. 2015; 40(12): 2570-2582, doi: 10.1007/s11064-014-1481-1, indexed in Pubmed: 25428182

26. Escartin C, Galea E, Lakatos A, et al. Reactive astrocyte nomenclature, definitions, and future directions. Nat Neurosci. 2021; 24(3): 312-325, doi: 10.1038/s41593020-00783-4, indexed in Pubmed: 33589835.

27. Frade J, Pope S, Schmidt M, et al. Glutamate induces release of glutathione from cultured rat astrocytes--a possible neuroprotective mechanism? J Neurochem. 2008; 105(4): 1144-1152, doi: 10.1111/j.14714159.2008.05216.x, indexed in Pubmed: 18182055.

28. Franklin R, Gilson J, Blakemore W. Local recruitment of remyelinating cells in the repair of demyelination in the central nervous system. J Neurosci Res. 1997; 50(2): 337-344, doi: 10.1002/(sici)1097-4547(19971015)50:2< 337::aid-jnr21>3.0.co;2-3, indexed in Pubmed: 9373042.

29. Fröhlich N, Nagy B, Hovhannisyan A, et al. Fate of neuron-glia synapses during proliferation and differentiation of NG2 cells. J Anat. 2011; 219(1): 18-32, doi: 10.1111/j.1469-7580.2011.01392.x, indexed in Pubmed: 21592101

30. Giotakos $\mathrm{O}$. Is psychosis a dysmyelination-related information-processing disorder? Psychiatriki. 2019; 30(3): 245-255, doi: 10.22365/jpsych.2019.303.245, indexed in Pubmed: 31685456.

31. Girouard H, ladecola C. Neurovascular coupling in the normal brain and in hypertension, stroke, and Alzheimer disease. J Appl Physiol (1985). 2006; 100(1): 328-335, doi: 10.1152/japplphysiol.00966.2005, indexed in Pubmed: 16357086

32. Goldmann T, Wieghofer $P$, Jordão MJ, et al. Origin, fate and dynamics of macrophages at central nervous system interfaces. Nat Immunol. 2016; 17(7): 797-805, doi: 10.1038/ni.3423, indexed in Pubmed: 27135602.

33. Hackett AR, Yahn SL, Lyapichev K, et al. Injury type-dependent differentiation of NG2 glia into heterogeneous astrocytes. Exp Neurol. 2018; 308: 72-79, doi: 10.1016/j. expneurol.2018.07.001, indexed in Pubmed: 30008424

34. Halassa MM, Fellin T, Haydon PG. Tripartite synapses: roles for astrocytic purines in the control of synaptic physiology and behavior. Neuropharmacology. 2009 57(4): 343-346, doi: 10.1016/j.neuropharm.2009.06.031, indexed in Pubmed: 19577581.

35. Hanisch UK. Functional diversity of microglia - how heterogeneous are they to begin with? Front Cell Neurosci. 2013; 7: 65, doi: 10.3389/fncel.2013.00065, indexed in Pubmed: 23717262.

36. Henneke $P$, Kierdorf $K$, Hall $\sqcup$, et al. Perinatal development of innate immune topology. Elife. 2021; 10, doi: 10.7554/ eLife.67793, indexed in Pubmed: 34032570.

37. Honsa P, Pivonkova H, Dzamba D, et al. Polydendrocytes display large lineage plasticity following focal cerebral ischemia. PLoS One. 2012; 7(5): e36816, doi: 10.1371/ journal.pone.0036816, indexed in Pubmed: 22590616.

38. Honsa P, Valny M, Kriska J, et al. Generation of reactive astrocytes from NG2 cells is regulated by sonic hedgehog. Glia. 2016; 64(9): 1518-1531, doi: 10.1002/glia.23019, indexed in Pubmed: 27340757.

39. Hsuan YCY, Lin CH, Chang CP, et al. Mesenchymal stem cell-based treatments for stroke, neural trauma, and heat stroke. Brain Behav. 2016; 6(10): e00526, doi: 10.1002/ brb3.526, indexed in Pubmed: 27781140.

40. Hughes EG, Kang SH, Fukaya M, et al. Oligodendrocyte progenitors balance growth with self-repulsion to achieve homeostasis in the adult brain. Nat Neurosci. 2013; 16(6): 668-676, doi: 10.1038/nn.3390, indexed in Pubmed: 23624515.

41. Iadecola $C$. The neurovascular unit coming of age: a journey through neurovascular coupling in health and disease. Neuron. 2017; 96(1): 17-42, doi: 10.1016/j. neuron.2017.07.030, indexed in Pubmed: 28957666.

42. Kana V, Desland F, Casanova-Acebes M, et al. CSF-1 controls cerebellar microglia and is required for motor function and social interaction. J Exp Med. 2019; 216(10): 2265-2281, doi: 10.1084/jem.20182037, indexed in Pubmed: 31350310.

43. Khakh BS, Deneen B. The emerging nature of astrocyte diversity. Annu Rev Neurosci. 2019; 42: 187-207, doi: 10.1146/annurev-neuro-070918-050443, indexed in Pubmed: 31283899.

44. Khakh BS, Sofroniew MV. Diversity of astrocyte functions and phenotypes in neural circuits. Nat Neurosci. 2015; 18(7): 942-952, doi: 10.1038/nn.4043, indexed in Pubmed: 26108722.

45. Khoshnam SE, Winlow W, Farbood Y, et al. Pathogenic mechanisms following ischemic stroke. Neurol Sci. 2017; 38(7): 1167-1186, doi: 10.1007/s10072-017-2938-1, indexed in Pubmed: 28417216.

46. Kimelberg HK, Nedergaard M. Functions of astrocytes and their potential as therapeutic targets. Neurotherapeutics. 2010; 7(4): 338-353, doi: 10.1016/j.nurt.2010.07.006, indexed in Pubmed: 20880499.

47. Kimelberg HK. Functions of mature mammalian astrocytes: a current view. Neuroscientist. 2010; 16(1): 79-106, doi: 10.1177/1073858409342593, indexed in Pubmed: 20236950.

48. Kimelberg HK. The problem of astrocyte identity. Neurochem Int. 2004; 45(2-3): 191-202, doi: 10.1016/j. neuint.2003.08.015, indexed in Pubmed: 15145537.

49. Köhler S, Winkler U, Hirrlinger J. Heterogeneity of astrocytes in grey and white matter. Neurochem Res. 2021; 46(1): 3-14, doi: 10.1007/s11064-019-02926-x, indexed in Pubmed: 31797158.

50. Kowiański P, Lietzau G, Steliga A, et al. The astrocytic contribution to neurovascular coupling--still more questions than answers? Neurosci Res. 2013; 75(3): 171-183, doi: 10.1016/j. neures.2013.01.014, indexed in Pubmed: 23419863.

51. Kuhn S, Gritti L, Crooks D, et al. Oligodendrocytes in development, myelin generation and beyond. Cells. 2019; 8(11), doi: 10.3390/cells8111424, indexed in Pubmed: 31726662.

52. Lago-Baldaia I, Fernandes VM, Ackerman SD. More than mortar: glia as architects of nervous system development and disease. Front Cell Dev Biol. 2020; 8: 611269, doi: 10.3389/fcell.2020.611269, indexed in Pubmed: 33381506.

53. Lawson $\sqcup$, Perry VH, Dri P, et al. Heterogeneity in the distribution and morphology of microglia in the normal adult mouse brain. Neuroscience. 1990; 39(1): 151-170, doi: 10.1016/0306-4522(90)90229-w, indexed in Pubmed: 2089275 . 
54. Li Q, Barres BA. Microglia and macrophages in brain homeostasis and disease. Nat Rev Immunol. 2018; 18(4): 225-242, doi: 10.1038/nri.2017.125, indexed in Pubmed: 29151590.

55. Liddelow SA, Barres BA. Reactive astrocytes: production, function, and therapeutic potential. Immunity. 2017; 46(6): 957-967, doi: 10.1016/j.immuni.2017.06.006, indexed in Pubmed: 28636962.

56. Liddelow SA, Guttenplan KA, Clarke LE, et al. Neurotoxic reactive astrocytes are induced by activated microglia. Nature. 2017; 541(7638): 481-487, doi: 10.1038/nature21029, indexed in Pubmed: 28099414.

57. Liebner S, Dijkhuizen RM, Reiss $Y$, et al. Functional morphology of the blood-brain barrier in health and disease. Acta Neuropathol. 2018; 135(3): 311-336, doi: 10.1007/ s00401-018-1815-1, indexed in Pubmed: 29411111.

58. Liu LR, Liu JC, Bao JS, et al. Interaction of microglia and astrocytes in the neurovascular unit. Front Immunol. 2020; 11: 1024, doi: 10.3389/fimmu.2020.01024, indexed in Pubmed: 32733433.

59. Magistretti PJ, Allaman I. A cellular perspective on brain energy metabolism and functional imaging. Neuron. 2015; 86(4): 883-901, doi: 10.1016/j.neuron.2015.03.035, indexed in Pubmed: 25996133.

60. Martins-Macedo J, Lepore AC, Domingues HS, et al. Glial restricted precursor cells in central nervous system disorders: current applications and future perspectives. Glia. 2021; 69(3): 513-531, doi: 10.1002/glia.23922, indexed in Pubmed: 33052610.

61. Masuda T, Sankowski R, Staszewski O, et al. Microglia heterogeneity in the single-cell era. Cell Rep. 2020; 30(5): 1271-1281, doi: 10.1016/j.celrep.2020.01.010, indexed in Pubmed: 32023447.

62. Matcovitch-Natan O, Winter DR, Giladi A, et al. Microglia development follows a stepwise program to regulate brain homeostasis. Science. 2016; 353(6301): aad8670, doi: 10.1126/science.aad8670, indexed in Pubmed: 27338705.

63. Matyash V, Kettenmann $\mathrm{H}$. Heterogeneity in astrocyte morphology and physiology. Brain Res Rev. 2010; 63(1-2): 2-10, doi: 10.1016/j.brainresrev.2009.12.001, indexed in Pubmed: 20005253.

64. Menassa DA, Gomez-Nicola D. Microglial dynamics during human brain development. Front Immunol. 2018; 9: 1014, doi: 10.3389/fimmu.2018.01014, indexed in Pubmed: 29881376.

65. Moshrefi-Ravasdjani B, Dublin P, Seifert G, et al. Changes in the proliferative capacity of NG2 cell subpopulations during postnatal development of the mouse hippocampus. Brain Struct Funct. 2017; 222(2): 831-847, doi: 10.1007/s00429-016-1249-2, indexed in Pubmed: 27306788.

66. Murtie JC, Macklin WB, Corfas G. Morphometric analysis of oligodendrocytes in the adult mouse frontal cortex. J Neurosci Res. 2007; 85(10): 2080-2086, doi: 10.1002/ jnr.21339, indexed in Pubmed: 17492793.

67. Nishiyama A, Komitova M, Suzuki R, et al. Polydendrocytes (NG2 cells): multifunctional cells with lineage plasticity. Nat Rev Neurosci. 2009; 10(1): 9-22, doi: 10.1038/ nrn2495, indexed in Pubmed: 19096367.

68. Parri HR, Crunelli V. The role of $\mathrm{Ca} 2+$ in the generation of spontaneous astrocytic $\mathrm{Ca} 2+$ oscillations. Neuro- science. 2003; 120(4): 979-992, doi: 10.1016/s03064522(03)00379-8, indexed in Pubmed: 12927204.

69. Pelvig DP, Pakkenberg $H$, Stark AK, et al. Neocortical glial cell numbers in human brains. Neurobiol Aging. 2008; 29(11): 1754-1762, doi: 10.1016/j.neurobiolaging.2007.04.013, indexed in Pubmed: 17544173.

70. Ransom BR, Butt AM, Black JA. Ultrastructural identification of HRP-injected oligodendrocytes in the intact rat optic nerve. Glia. 1991; 4(1): 37-45, doi: 10.1002/ glia.440040105, indexed in Pubmed: 1828785.

71. Richardson WD, Young KM, Tripathi RB, et al. NG2glia as multipotent neural stem cells: fact or fantasy? Neuron. 2011; 70(4): 661-673, doi: 10.1016/j.neuron.2011.05.013, indexed in Pubmed: 21609823.

72. Rivera AD, Chacon-De-La-Rocha I, Pieropan F, et al. Keeping the ageing brain wired: a role for purine signalling in regulating cellular metabolism in oligodendrocyte progenitors. Pflugers Arch. 2021; 473(5): 775-783, doi: 10.1007/s00424-021-02544-z, indexed in Pubmed: 33712969.

73. Rivers LE, Young KM, Rizzi $M$, et al. PDGFRA/NG2 glia generate myelinating oligodendrocytes and piriform projection neurons in adult mice. Nat Neurosci. 2008; 11(12): 1392-1401, doi: 10.1038/nn.2220, indexed in Pubmed: 18849983.

74. Robins SC, Kokoeva MV. NG2-Glia, a new player in energy balance. Neuroendocrinology. 2018; 107(3): 305-312, doi: 10.1159/000488111, indexed in Pubmed: 29506015.

75. Schaeffer $S$, ladecola $C$. Revisiting the neurovascular unit. Nat Neurosci. 2021; 24(9): 1198-1209, doi: 10.1038/ s41593-021-00904-7, indexed in Pubmed: 34354283.

76. Schirmer L, Schafer DP, Bartels T, et al. Diversity and function of glial cell types in multiple sclerosis. Trends Immunol. 2021; 42(3): 228-247, doi: 10.1016/j.it.2021.01.005, indexed in Pubmed: 33593693.

77. Schoenwolf GC, Bleyl SB, Brauer PR, Francis-West PH. Develoment of the central nervous system. Larsen's human embryology. 6th ed. Elsevier, Philadelphia 2020: 191-227.

78. Sharma K, Bisht K, Eyo UB. A comparative biology of microglia across species. Front Cell Dev Biol. 2021; 9: 652748, doi: 10.3389/fcell.2021.652748, indexed in Pubmed: 33869210.

79. Sofroniew MV, Vinters HV. Astrocytes: biology and pathology. Acta Neuropathol. 2010; 119(1): 7-35, doi: 10.1007/ s00401-009-0619-8, indexed in Pubmed: 20012068.

80. Sofroniew MV. Astrocyte reactivity: subtypes, states, and functions in CNS innate immunity. Trends Immunol. 2020; 41(9): 758-770, doi: 10.1016/j.it.2020.07.004, indexed in Pubmed: 32819810.

81. Sofroniew MV. Molecular dissection of reactive astrogliosis and glial scar formation. Trends Neurosci. 2009; 32(12): 638-647, doi: 10.1016/j.tins.2009.08.002, indexed in Pubmed: 19782411.

82. Staszewski O, Hagemeyer N. Unique microglia expression profile in developing white matter. BMC Res Notes. 2019; 12(1): 367, doi: 10.1186/s13104-019-4410-1, indexed in Pubmed: 31262353.

83. Steliga A, Kowiański P, Czuba E, et al. Neurovascular unit as a source of ischemic stroke biomarkers-limitations of experimental studies and perspectives for clinical application. Transl Stroke Res. 2020; 11(4): 553-579, 
doi: 10.1007/s12975-019-00744-5, indexed in Pubmed: 31701356.

84. Stremmel C, Schuchert R, Wagner F, et al. Yolk sac macrophage progenitors traffic to the embryo during defined stages of development. Nat Commun. 2018; 9(1): 75, doi: 10.1038/s41467-017-02492-2, indexed in Pubmed: 29311541.

85. Takano T, Tian GF, Peng W, et al. Astrocyte-mediated control of cerebral blood flow. Nat Neurosci. 2006; 9(2): 260-267, doi: 10.1038/nn1623, indexed in Pubmed: 16388306.

86. Thion MS, Low D, Silvin A, et al. Microbiome influences prenatal and adult microglia in a sex-specific manner. Cell. 2018; 172(3): 500-516.e16, doi: 10.1016/j. cell.2017.11.042, indexed in Pubmed: 29275859.

87. Torper O, Götz M. Brain repair from intrinsic cell sources: turning reactive glia into neurons. Prog Brain Res. 2017; 230: 69-97, doi: 10.1016/bs.pbr.2016.12.010, indexed in Pubmed: 28552236.

88. Torper O, Ottosson DR, Pereira M, et al. In vivo reprogramming of striatal NG2 glia into functional neurons that integrate into local host circuitry. Cell Rep. 2015; 12(3): 474-481, doi: 10.1016/j.celrep.2015.06.040, indexed in Pubmed: 26166567.

89. Utz SG, See P, Mildenberger W, et al. Early fate defines microglia and non-parenchymal brain macrophage development. Cell. 2020; 181(3): 557-573.e18, doi: 10.1016/j. cell.2020.03.021, indexed in Pubmed: 32259484.

90. Valny $M$, Honsa P, Kriska J, et al. Multipotency and therapeutic potential of NG2 cells. Biochem Pharmacol. 2017; 141: 42-55, doi: 10.1016/j.bcp.2017.05.008, indexed in Pubmed: 28522408.

91. Valny $M$, Honsa $P$, Waloschkova $E$, et al. A single-cell analysis reveals multiple roles of oligodendroglial lineage cells during post-ischemic regeneration. Glia. 2018; 66(5): 1068-1081, doi: 10.1002/glia.23301, indexed in Pubmed: 29393544.

92. Verkhratsky A, Ho MS, Zorec R, et al. The concept of neuroglia. Adv Exp Med Biol. 2019; 1175: 1-13, doi: 10.1007/978-981-13-9913-8_1, indexed in Pubmed: 31583582.
93. Verkhratsky A, Kettenmann H. Calcium signalling in glial cells. Trends Neurosci. 1996; 19(8): 346-352, doi: 10.1016/0166-2236(96)10048-5, indexed in Pubmed: 8843604.

94. Verkhratsky A, Sofroniew MV, Messing A, et al. Neurological diseases as primary gliopathies: a reassessment of neurocentrism. ASN Neuro. 2012; 4(3), doi: 10.1042/ AN20120010, indexed in Pubmed: 22339481.

95. Werner Y, Mass E, Ashok Kumar P, et al. Cxcr4 distinguishes HSC-derived monocytes from microglia and reveals monocyte immune responses to experimental stroke. Nat Neurosci. 2020; 23(3): 351-362, doi: 10.1038/s41593020-0585-y, indexed in Pubmed: 32042176.

96. Wlodarczyk A, Holtman IR, Krueger M, et al. A novel microglial subset plays a key role in myelinogenesis in developing brain. EMBO J. 2017; 36(22): 3292-3308, doi: 10.15252/embj.201696056, indexed in Pubmed: 28963396.

97. Zhao JW, Raha-Chowdhury R, Fawcett JW, et al. Astrocytes and oligodendrocytes can be generated from NG2 + progenitors after acute brain injury: intracellular localization of oligodendrocyte transcription factor 2 is associated with their fate choice. Eur J Neurosci. 2009; 29(9): 1853-1869, doi: 10.1111/j.1460-9568.2009.06736.x, indexed in Pubmed: 19473238.

98. Zhou YD. Glial regulation of energy metabolism. Adv Exp Med Biol. 2018; 1090: 105-121, doi: 10.1007/978-98113-1286-1_6, indexed in Pubmed: 30390287.

99. Zhu X, Hill RA, Dietrich D, et al. Age-dependent fate and lineage restriction of single NG2 cells. Development. 2011; 138(4): 745-753, doi: 10.1242/dev.047951, indexed in Pubmed: 21266410.

100.Zonta M, Angulo MC, Gobbo S, et al. Neuron-to-astrocyte signaling is central to the dynamic control of brain microcirculation. Nat Neurosci. 2003; 6(1): 43-50, doi: 10.1038/nn980, indexed in Pubmed: 12469126.

101.Zonta M, Carmignoto G. Calcium oscillations encoding neuron-to-astrocyte communication. J Physiol Paris. 2002; 96(3-4): 193-198, doi: 10.1016/s0928-4257(02)00006-2, indexed in Pubmed: 12445896. 